TT Revista del instituto de ciencias

$\int \begin{aligned} & \text { JuRÍDICAS DE PUEBLA, MÉXICO, AÑO V } \\ & \text { No. 28, JULIO-DICIEMBRE DE 2011, PP. 204-224 }\end{aligned}$

\title{
El derecho a la igualdad y el principio de no discriminación: la obligación del gobierno de México para realizar la armonización legislativa con perspectiva de género* The Right to Equality and the Principle of Non-Discrimination. The Mexican's Government's Obligation to Realize the Harmonization of Law with Mainstreaming
}

\author{
Elizardo Rannauro Melgarejo**
}

\section{RESUMEN}

El presente articulo hace referencia a los avances establecidos en la agenda internacional del derecho a la igualdad y el principio de no discriminación, asi como a los principios de igualdad entre la mujer y el hombre y el de no discriminación, establecidos en el marco juridico constitucional mexicano, que establecen la obligación del Estado mexicano de realizar la armonización legislativa con perspectiva de género al derecho interno mexicano, para la protección jurídica en la defensa y promoción de los derechos humanos y la autonomía de las mujeres.

PALABRAS CLAVE: Igualdad, no discriminación, derechos humanos.

\section{ABSTRACT}

The present article makes reference to the established advances in the international agenda to the right of equality and non-discrimination principle. As well as non-discrimination equality's principle among men and women established at the Mexican's constitutional legal frame, which established the obligation of Mexican State to make harmonization of law with the mainstreaming to the Mexican international right, for the juridical protection in defense and promotion of human rights and women autonomy.

KEY WORDS: Equality, non-discrimination, human rights.

${ }^{*}$ Recibido: 29 de junio de 2011. Aprobado: 21 de julio de 2011.

** Presidente del Instituto para la Investigación de los Derechos Humanos y Estudios de Género, A. c., México.

(elizardorannauro@hotmail.com). 


\section{Sumario}

1. Antecedentes

2. La igualdad juridica y la no discriminación en el ámbito internacional

3. La Convención de Viena sobre el Derecho de los Tratados y la norma pacta sunt servanda

4. La relación constitucional y su relación con los tratados internacionales de derechos

humanos

5. La igualdad jurídica y no discriminación en el ámbito mexicano

6. La armonización legislativa con perspectiva de género al derecho interno en México

7. Conclusiones

\section{Antecedentes}

En la agenda internacional la mayoría de los países se han reunido a efecto de establecer acuerdos para eliminar todos aquellos obstáculos que existen para el desarrollo político, económico, social, cultural y medioambiental en el mundo, sin duda dos de estos obstáculos son la desigualdad y la discriminación.

A lo largo de la historia y durante muchos años en diversos acuerdos internacionales del sistema universal y del sistema interamericano quedaron establecidos el derecho a la igualdad y el principio de no discriminación, desafortunadamente a la fecha en la mayoría de los casos no se aplican para la protección jurídica y la defensa y promoción de los derechos humanos, particularmente para la autonomía de las mujeres.

Hay que recordar que en el mes de septiembre de 2000, la Asamblea General de la Organización de las Naciones Unidas decidió "promover la igualdad entre los sexos y la autonomía de la mujer como medios eficaces de combatir la pobreza, el hambre y las enfermedades y de estimular un desarrollo verdaderamente sostenible", 1 a efecto de lograr la igualdad entre mujeres y hombres y que ésta no debe excluirse o limitarse, en virtud de que aún persisten las desigualdades y la discriminación que hace denotar una serie de tratos diferenciados entre mujeres y hombres, limitando el acceso a las mismas oportunidades y al ejercicio de los derechos humanos.

El principio de igualdad debe dilucidarse como reconocer las diferencias que existen entre las mujeres y hombres, considerando factores como la edad, el género, la discapacidad, la situación de vulnerabilidad, la raza, las diversas opiniones, la identidad, entre muchas otras caracteristicas que deben ser analizadas para considerar una igualdad real y efectiva.

\footnotetext{
1 Organización de las Naciones Unidas. a/55/L.2 "Declaración de los Objetivos del Milenio", onu, 2000.
} 
La igualdad entre mujeres y hombres supone, por ende, que la sociedad dé el mismo valor a sus semejanzas y diferencias, y a los papeles que desempeñan. "Requiere que tanto los hombres como las mujeres sean miembros de pleno derecho en su familia, su comunidad y su sociedad", ${ }^{2}$ en la que debe considerarse una igualdad real y efectiva, que va más allá de solo una inclusión de aquella que se encuentra garantiza en la aplicabilidad de una normatividad nacional e internacional, debiendo impulsar la incorporación de la perspectiva de género ${ }^{3}$ como mecanismos de análisis social.

\section{La igualdad jurídica y la no discriminación en el ámbito internacional}

Los avances en el plano internacional han sido muchos para regular, de forma constante, el derecho a la igualdad y el principio de no discriminación, en los diversos acuerdos y tratados internacionales en materia de derechos humanos.

En el Sistema Universal y con la adopción de la Declaración Universal de los Derechos Humanos en 1948, los Estados reafirmaron su fe en los derechos humanos en la dignidad inherente y el valor de la persona humana y en la igualdad de derechos entre hombres y mujeres al articular que "Todos los seres humanos nacen libres e iguales en dignidad y derechos y, dotados con conciencia, deben comportarse fraternalmente los unos con los otros", ${ }^{4}$ incorporando además el derecho a la no discriminación por ningún tipo, incluida en el texto del artículo $2^{\circ}$ de esta Declaración.

Los Estados parte se comprometieron desde entonces a trabajar unidos para promover el progreso social y elevar el nivel de vida dentro de un concepto más amplio de la libertad, para lo cual se dieron a la tarea de formular instrumentos de carácter vinculante que garantizaran el logro de este objetivo.

Años después, en 1966 se adoptó el Pacto Internacional de Derechos Civiles y Políticos en los cuales se reconocen a la vida, libertad y seguridad personales, el

\footnotetext{
2 Extracto del Marco de aplicación de la estrategia de integración de la perspectiva de género en todas las actividades de la unESCO 2002-2007.

${ }^{3}$ Se define la estrategia de Incorporación de la Perspectiva de Género como "[...] el proceso de evaluación de las consecuencias para las mujeres y los hombres de cualquier actividad planificada, inclusive las leyes, políticas o programas, en todos los sectores y a todos los niveles. Es una estrategia destinada a hacer que las preocupaciones y experiencias de las mujeres, así como de los hombres, sean un elemento integrante de la elaboración, la aplicación, la supervisión y la evaluación de las políticas y los programas en todas las esferas políticas, económicas y sociales, a fin de que las mujeres y los hombres se beneficien por igual y se impida que se perpetúe la desigualdad. El objetivo final es lograr la igualdad entre los géneros". Organización de las Naciones Unidas, Consejo Económico y Social de la Organización de las Naciones Unidas, Conclusiones convenidas, E/1997/L.30, 14 de julio de 1997.

4 Artículo 1º de la Declaración Universal de los Derechos Humanos, onu, 1948.
} 
libre tránsito, entre otros, incluyendo que los Estados parte tienen la obligación de respetarla sin distinción ${ }^{5}$ y el compromiso de garantizar a "hombres y mujeres la igualdad en el goce de todos los derechos civiles y políticos" ${ }^{\prime 6}$ incluidos en ese Pacto. Aunado a éste, se crear el Pacto Internacional de Derechos Económicos, Sociales y Culturales que norma el compromiso de los Estados a adoptar medidas separadas o conjuntas con otros, para el ejercicio pleno de los derechos humanos ahí reconocidos, sin discriminación alguna para el desarrollo económico, social y cultural.

Desde 1975, la onu ha celebrado una serie de conferencias mundiales lo que ha facilitado una plataforma para formular y fomentar a escala mundial nuevos objetivos clave en materia de desarrollo, expresando claramente la necesidad de incorporar la igualdad entre mujeres y hombres, los derechos humanos de las mujeres, en el desarrollo social y la paz, entre otros.

En lo que respecta a las conferencias internacionales de las mujeres, es necesario destacar los acuerdos realizados en dos de ellas:

La Primera Conferencia Mundial de la Mujer, realizada en México en el año de 1975, en cuya declaración política se subraya que:

[...] las mujeres y los hombres de todos los paises deben tener iguales derechos y deberes, y que incumbe a todos los Estados crear las condiciones necesarias para que aquéllas los alcancen y puedan ejercerlos [...] Además de acordar la realización de una Convención para eliminar todas las formas de Discriminación contra la Mujer.

En este sentido, la Declaración establece la igualdad en los ámbitos político, laboral y civil, sobre todo se reconocen dos temas fundamentales: los derechos humanos y la violencia, aunque sólo en la esfera familiar.

Por su parte, en la Tercera Conferencia Mundial de la Mujer, celebrada en Nairobi, en 1985, se adoptan

Las Estrategias de Nairobi orientadas hacia el futuro para el adelanto de la mujer [...], abarcando un enfoque más amplio del adelanto de la mujer: La igualdad, lejos de ser una cuestión aislada, abarca toda la esfera de la vida humana. Establecen por violencia doméstica, un obstáculo para la equidad y una ofensa a la dignidad humana.

Ahora bien, después de 4 años de la Primera Conferencia Mundial de la Mujer de 1975, y de las negociaciones, se adopta en la Asamblea General en 1979 la Convención sobre la Eliminación de Todas las Formas de Discriminación contra

\footnotetext{
${ }^{5}$ Artículo 2.1 del Pacto Internacional de Derechos Civiles y Políticos.

${ }^{6}$ Artículo $3^{\circ}$ del Pacto Internacional de Derechos Civiles y Políticos.
} 
la Mujer, ${ }^{7}$ CEDAW, por sus siglas en inglés, que es un tratado internacional de derechos humanos que protege los derechos y libertades fundamentales de las mujeres. Conforme a la CEDAW, la obligación adquirida por los Estados parte es la de tomar todas las medidas apropiadas para eliminar la discriminación contra las mujeres, la cual no se limita únicamente al ámbito público sino que también se extiende a la esfera privada, cubriendo la discriminación practicada por cualesquiera personas, organizaciones o empresas.

Así en su artículo 30. hace mención que "[...] se deberá tomar en todas las esferas política, social, económica y cultural, todas las medidas apropiadas, incluso de carácter legislativo, para asegurar el pleno desarrollo y adelanto de las mujeres, con el objeto de garantizarle el ejercicio y el goce de los derechos humanos y las libertades fundamentales en igualdad de condiciones con los hombres".

Con el fin de examinar los progresos alcanzados en la aplicación de la CEDAW por los Estados parte, se estableció el Comité de las Naciones Unidas para la Eliminación de la Discriminación contra la Mujer. ${ }^{8}$ La tarea principal del Comité es vigilar y evaluar la correcta aplicación de la CEDAw y colaborar con los Estados parte para eliminar la discriminación contra las mujeres. Para llevar a cabo esta tarea, los gobiernos nacionales envían informes periódicos al Comité de la CEDAW, cuando menos cada cuatro años, o cuando el Comité así lo solicita, detallando las medidas legislativas, judiciales, administrativas o de otra índole que han adoptado en cumplimiento de la Convención y sobre los progresos realizados en este sentido.

El Comité de Expertas de la CEDAw al revisar los informes de los distintos países detectó patrones de violación a los derechos humanos de las mujeres que se repiten en distintas partes de mundo, por ello publicó recomendaciones generales. Dentro de las 27 recomendaciones generales que existen (hasta el año 2011), se encuentran las recomendaciones número 12 y 19 que se refieren a la "Violencia en contra de las Mujeres", la cual ha enmarco que la violencia contra las mujeres es una forma de discriminación que inhibe o limita las oportunidades y capacidades de las mujeres de gozar el ejercicio de sus derechos humanos y libertades en igualdad con los hombres.

La recomendación general número 12, publicada en 1989, recomienda a los Estados parte que incluyan en sus informes referencias sobre: la legislación vigente para protegerlas de la frecuencia de cualquier tipo de violencia en la vida cotidiana (la violencia sexual, malos tratos en el ámbito familiar, acoso sexual

7 Ratificada por el gobierno de México en 1981.

${ }^{8}$ El Comité está compuesto por 23 integrantes de gran prestigio moral y competencia en la situación de la mujer, elegidos por los Estados parte de la Convención entre sus nacionales, y quienes ejercen sus funciones a título personal. 
en el lugar de trabajo, etcétera); otras medidas adoptadas para erradicar esa violencia; servicios de apoyo a las mujeres que sufren agresiones o malos tratos, y datos estadísticos sobre la frecuencia de cualquier tipo de violencia contra las mujeres y sobre las mujeres víctimas de la violencia.

En la Recomendación número $19,{ }^{9}$ publicada en 1991, destacan lo que los derechos y libertades de las mujeres comprenden: el derecho a la vida; el derecho a no ser sometidas a torturas o a tratos o penas crueles, inhumanas o degradantes; a la protección en condiciones de igualdad con arreglo a normas humanitarias en tiempo de conflicto armado internacional o interno; a la libertad y a la seguridad personal; igualdad ante la ley; igualdad en la familia; al más alto nivel posible de salud física y mental; y el derecho a condiciones de empleo justas y favorables, y que éstos deben garantizarse de forma igualitaria a los hombres.

Por último y de manera particular, el Comité de Derechos Humanos de la onU emitió la Observación General número 28 intitulada "Igualdad de derechos entre hombres y mujeres", ${ }^{10}$ en la que se fundamenta el artículo tercero del Pacto lnternacional de Derechos Civiles y Políticos. En ella se suscribe la importancia de la igualdad entre mujeres y hombres en la misma proporción que la protección de los derechos humanos que protege.

Observa con especial cuidado que el principio de igualdad requiere acciones positivas por parte de los Estados, sin limitarlo únicamente a la protección jurídica. En el mismo texto, el Comité advierte que aún persisten las desigualdades entre mujeres y hombres, que se agudizan por las tradiciones, historia, cultura y las creencias religiosas. Por tanto, insta a los Estados parte de informar y reaccionar sobre la desigualdad que afecta en mayor medida a las mujeres, y que éstos deben realizar todas las acciones y medidas en los ámbitos religioso, laboral, cultural y en salud, principalmente, para reducir dichas diferencias.

En el sistema interamericano, la Convención Americana sobre Derechos Humanos, emitida en la Organización de los Estados Americanos (ozA), instaura de forma correlativa los principios de igualdad y no discriminación al establecer que "Todas las personas son iguales ante la ley. En consecuencia, tienen derecho, sin discriminación, a igual protección de la ley”."

Es importante destacar que el gobierno de México reconoce la competencia de todos los órganos de supervisión de los tratados internacionales de derechos

\footnotetext{
${ }^{9}$ Rannauro Melgarejo, Elzardo. Manual: Convención sobre la Eliminación de Todas las Formas de Discriminación contra las Mujeres y su Protocolo Facultativo, CEDAW, SRE/UnIFEM/PUDo, México, 2007, p. 166.

10 Organización de las Naciones Unidas, Comité de Derechos Humanos. "Observación General número 28. Igualdad de derechos entre hombres y mujeres", ccpr/c/21/Rev.1/Add.10, 29 de marzo de 2000.

"Artículo 24 "Igualdad ante la Ley" de la Convención Americana sobre Derechos Humanos, OEA, 1969.
} 
humanos ${ }^{12}$ incluyendo la competencia de prácticamente todos éstos para recibir comunicaciones individuales e incluso realizar investigaciones.

Es necesario señalar que la violencia contra las mujeres es un instrumento para impedir o anular el ejercicio pleno de los derechos humanos de las mujeres $\mathrm{y}$, por ende, la reducción de la posibilidad de una vida libre de violencia y la igualdad real entre mujeres y hombres, y en esta tesitura la Convención Interamericana para Prevenir, Sancionar y Erradicar la Violencia contra la Mujer, "Convención de Belém Do Pará", señala que los Estados parte deben

[...] Incluir en su legislación interna normas penales, civiles y administrativas, así como las de otra naturaleza que sean necesarias para prevenir, sancionar y erradicar la violencia contra la mujer y adoptar las medidas administrativas apropiadas que sean del caso; [...] Tomar todas las medidas apropiadas, incluyendo medidas de tipo legislativo, para modificar o abolir leyes y reglamentos vigentes, o para modificar prácticas jurídicas o consuetudinarias que respalden la persistencia o la tolerancia de la violencia contra la mujer. ${ }^{13}$

Por ende, los Estados parte de la Convención se comprometen a fomentar el conocimiento y la observancia del derecho de la mujer a una vida libre de violencia, y el derecho de la mujer a que se respeten y protejan sus derechos humanos y a garantizar el "derecho a igualdad de protección ante la ley y de la ley", ${ }^{14}$ entre otros derechos.

La Convención de Belém do Pará era el único instrumento dentro del sistema interamericano que, al 25 de octubre de 2004, no contaba con un mecanismo de seguimiento formal, los Estados parte de la Convención adoptaron el Estatuto del Mecanismo de Seguimiento de la Implementación de la Convención Interamericana para Prevenir, Sancionar y Erradicar la Violencia contra la Mujer, en ocasión de la Conferencia de Estados parte celebrada en Washington, D. c., el 26 de octubre de 2004.

El Mecanismo busca subsanar deficiencias en el cumplimiento de la Convención, toda vez que, a pesar de los logros obtenidos durante los últimos años mediante la adopción de políticas, programas y planes nacionales, no existe información suficiente ni registros que permitan evaluar la magnitud del problema

\footnotetext{
12 Comité de Derechos Humanos, Comité de Derechos Económicos, Sociales y Culturales, Comité para la Eliminación de la Discriminación Racial, Comité para la Eliminación de Todas las Formas de Violencia contra las Mujeres, Comité contra la Tortura, Comité sobre los Derechos del Niño, Comité sobre los Derechos de Todos los Trabajadores Migratorios y sus Familias.

13 Artículo $7^{\circ}$ de la Convención Interamericana para Prevenir, Sancionar y Erradicar la Violencia contra la Mujer.

${ }^{14}$ Artículo 4ํㅜ fracción f) de la Convención Interamericana para Prevenir, Sancionar y Erradicar la Violencia contra la Mujer.
} 
de la violencia contra las mujeres, ni tampoco los resultados concretos obtenidos en cada uno de los Estados parte.

Las recomendaciones generales emitidas por el Mecanismo de Seguimiento de la Convención, el documentos intitulado Respuestas al Cuestionario/Informe de País/Observaciones de la Autoridad Nacional Competente (ANC) ${ }^{15}$ a los que el gobierno del Estado de México debe revisar y cumplir en las diversas áreas de su competencia versan en los siguientes temas principales:

Considerar la emisión armónica de reformas legales o establecimiento de nuevas normas en los ámbitos penal, laboral, familiar y civil, entre otros, de manera tal que se concretizarán los mandatos de la Convención y las consideraciones de la Ley General de Acceso de las Mujeres a una Vida Libre de Violencia.

Tomar medidas apropiadas, incluyendo medidas de tipo legislativo, para modificar o abolir leyes y reglamentos vigentes, o para modificar prácticas jurídicas o consuetudinarias que respalden la persistencia o tolerancia de la violencia contra la Mujer.

En otro orden de ideas, e igualmente en el ámbito interamericano, es necesario recordar que la Comisión Interamericana de la Mujer de la oEA ${ }^{16}$ adoptó las resoluciones CIM/RES. 209/98 y AG/RES. 1625 (XXIX-0/99), del Programa Interamericano sobre la Promoción de los Derechos Humanos de la Mujer y la Equidad e lgualdad de Género, el cual señala entre sus objetivos específicos: "Promover la equidad e igualdad de género y los derechos humanos de la mujer, afianzando e impulsando: 1. La igualdad jurídica, real y formal de la mujer [...] 3. El acceso pleno e igualitario de la mujer al trabajo y a los recursos productivos [...]”.

Además recomienda que los gobiernos deban desarrollar las acciones para "Formular políticas públicas y estrategias e implementar acciones dirigidas a promover los derechos humanos de la mujer y la igualdad de género en todas las esferas de la vida pública y privada, considerando su diversidad y ciclos de vida, mediante la incorporación de una perspectiva de género".

En otro orden de ideas, cabe señalar que México es Estado parte de los ocho principales instrumentos internacionales vigentes de derechos humanos y sus protocolos facultativos en el sistema universal, y de los cinco principales instrumentos regionales en la materia y sus protocolos facultativos. En la última década México ha ratificado 13 instrumentos universales en materia de derechos humanos y 3 instrumentos regionales. ${ }^{17}$

\footnotetext{
15 Secretaria de Relaciones Exteriores. Mecanismo de Seguimiento Convención Belém Do Pará (mesecvi) México, México, 2008, pp. 105-112.

${ }_{16}$ Organismo intergubernamental más antiguo del mundo, creado en La Habana en 1928.

${ }_{17}$ Convención sobre el Estatuto de los Refugiados, 2000; Protocolo sobre el Estatuto de los Refugiados, 2000;
} 


\section{La Convención de Viena sobre el Derecho de los Tratados y la norma pacta sunt servanda}

La Convención de Viena sobre el Derecho de los Tratados, ratificada por México en septiembre de 1974, tiene como fundamental objetivo regular las relaciones internacionales entre distintos países, con fines a respetar los tratados, acuerdos y demás convenios que puedan suscitar entre dos o más.

Además, menciona específicamente que una parte no podrá invocar disposiciones de su derecho interno como justificación del incumplimiento de un tratado.

En este orden de ideas, el gobierno de México tiene el compromiso de traducir los instrumentos internacionales a la política interna de México, nexus diferentes órdenes de gobierno, particularmente atendiendo al principio de pacta sunt servanda, ${ }^{18}$ las partes están obligadas al cumplimiento de los tratados, de acuerdo con la buena fe.

Por ello, México está obligado a dar cabal cumplimiento a los preceptos contenidos en los tratados internacionales en materia de derechos humanos, por más, cuanto se trata de instrumentos relativos a la realización universal de los derechos fundamentales inherentes al ser humano.

No obstante, existen retos procedimentales que dificultan la aplicación real de los instrumentos. En otras palabras, ser Estado parte de la o las convenciones internacionales en materia de derechos humanos de las mujeres, en sí mismo no entraña per se la seguridad de que los derechos humanos de las mujeres serán respetados dentro de ese Estado, y para que dichos derechos sean una realidad en el país es necesario incorporarlos al ordenamiento nacional.

Es decir, en el caso de México, si bien los tratados internacionales, teóricamente, al ser ratificados por el Senado y publicarse en el Diario Oficial de la Fe-

Convención sobre el Estatuto de los Apátridas, 2000; Convención Interamericana para la Eliminación de Todas las Formas de Discriminación contra las Personas con Discapacidad, 2001; Protocolo Facultativo 1 del Pacto Internacional de Derechos Civiles y Políticos, 2002; Convención sobre la Imprescriptibilidad de los Crimenes de Guerra y de los 212 Crímenes de Lesa Humanidad, 2002; Protocolo Facultativo de la Convención sobre la Eliminación de Todas las Formas de Discriminación contra la Mujer, 2002; Protocolo Facultativo de la Convención sobre los Derechos del Niño relativo a la Venta de Niños, la Prostitución Infantil y la Utilización de los Niños en la Pornografía, 2002; Protocolo Facultativo de la Convención sobre los Derechos del Niño relativo a la Participación de Niños en Conflictos Armados, 2002; Convención Interamericana sobre Desaparición Forzada de Personas, 2002; Protocolo Facultativo de la Convención contra la Tortura y otros Tratos o Penas Crueles, Inhumanos o Degradantes, 2005; Estatuto de Roma, 2005; Protocolo Facultativo a la Convención Americana de Derechos Humanos en Materia de Abolición de la Pena de Muerte, 2007; Segundo Protocolo Facultativo al Pacto Internacional de Derechos Civiles y Políticos Destinado a Abolir la Pena de Muerte, 2007; Convención sobre los Derechos de las Personas con Discapacidad y su Protocolo Facultativo, 2007; Convención Internacional para Proteger a Todas las Personas contra las Desapariciones Forzadas, 2008.

18 El pacta sunt servanda de conformidad con el artículo 26 de la Convención de Viena sobre el Derecho de los Tratados se refiere a que "Todo tratado en vigor obliga a las partes y debe ser cumplido por ellas de buena fe". 
deración tienen aplicación inmediata en el país (son self-executing), lo cierto es que muchas de las disposiciones contenidas en las convenciones aún no han sido traducidas a la legislación interna para la defensa y promoción de los derechos.

\section{La relación constitucional y su relación con los tratados internacionales de derechos humanos}

Desde 1917 se ha incluido el principio de no discriminación en nuestro texto constitucional en el artículo $1^{\circ}$; sin embargo, se han suscitado una serie de modificaciones que convergen en proteger, hasta este año, a "las garantías individuales" de las personas, reconociendo derecho y libertades, por lo que el avance principal en el tema de igualdad se obtuvo hasta 1974 con la reforma al artículo $4^{\circ}$ constitucional, que establece la igualdad entre "el varón y la mujer" pero estableciéndola al ámbito legal, desafortunadamente en la realidad social aún se sumerge en un proceso de reconocimiento de los derechos humanos de las mujeres en igualdad con los de los hombres.

El artículo 133 constitucional aduce las características que debían considerarse en cualquier tratado internacional, siendo una limitante que éstos deberían estar acordes a lo que la Constitución establece, así como la particularidad de estar firmados y ratificados por el Estado mexicano, proveyendo que muchos instrumentos jurídicos internacionales puedan no ser adoptados en nuestro derecho interno, además que posiblemente tendría que pasar por una interpretación o consideración jurisdiccional para que tengan valor jurídico.

Empero, con la reforma constitucional en materia de derechos humanos publicada en 2011, se han consolidado avances importantes para garantizar la protección jurídica de los derechos humanos, en los cuales se integra la obligatoriedad de la autoridad de protegerlos, motivando investigaciones y sanciones para aquellas que incumplen. Además se le otorga un carácter constitucional al derecho de las niñas y los niños, a la alimentación, al deporte, entre otros derechos. Se otorga además, una obligatoriedad a todas las autoridades de implementar los compromisos contenidos en los instrumentos jurídicos internacionales. Ésta ya no se constriñe no solo a la voluntad políticas de dichas autoridades, sino advierte la probable responsabilidad administrativa o punitiva que pueden llegarse a dar por no considéralos.

Así no sólo involucra la igualdad de iure sino que además la prohibición de la discriminación por parte de las autoridades así como la facultad de investigar a sancionar si estas conductas son acreditables de una sanción. 
ELIZARDO RANNAURO MELGAREJO

\section{La igualdad jurídica y no discriminación en el ámbito mexicano}

En México existen progresos significativos en el caso particular del derecho a la igualdad y el principio de no discriminación consagrados en la agenda internacional, a favor del respeto y promoción de los derechos humanos, particularmente de los derechos humanos de las mujeres.

El 31 de diciembre de 1974 se efectuó la reforma al artículo $4^{\circ}$ de la Constitución política federal, que refiere que "El varón y la mujer son igualdad ante la ley", incentivando su aplicación solo en el contexto que una ley dirima controversias, o que solo persista un procedimiento, en sentido estricto; sin embargo, los ordenamientos jurídicos en México no han sido modificados del todo y hacer realidad el mandato constitucional de 1974, y aún en la realidad existen un número significativo de ordenamientos jurídicos discriminatorios hacia la mujer.

Sin embargo, después de varias décadas la Suprema Corte de Justicia de la Nación tuvo la necesidad de interpretar el principio de igualdad como un valor superior del orden jurídico mexicano,

[...] lo que significa que ha de servir de criterio básico para la producción normativa y su posterior interpretación y aplicación, y si bien es cierto que el verdadero sentido de la igualdad es colocar a los particulares en condiciones de poder acceder a derechos reconocidos constitucionalmente, lo que implica eliminar situaciones de desigualdad manifiesta, ello no significa que todos los individuos deban ser iguales en todo, ya que si la propia Constitución protege la propiedad privada, la libertad económica y otros derechos patrimoniales. ${ }^{19}$

Cabe señalar que nuestra Constitución ha referido la prohibición de la discriminación en su artículo $4^{\circ}$ constitucional, en que dilucida que

Queda prohibida toda discriminación motivada por origen étnico o nacional, el género, la edad, las discapacidades, la condición social, las condiciones de salud, la religión, las opiniones, las preferencias sexuales, el estado civil o cualquier otra que atente contra la dignidad humana y tenga por objeto anular o menoscabar los derechos y libertades de las personas.

Estas condiciones integradas en el artículo anterior han sido reconocidas paulatinamente que, aunque lento, busca elevar a rango constitucional las condiciones

19 Suprema Corte de Justicia de la Nación, tesis 1a./J.81/2004, "IGUALDAD. Limites a eSTE PrincipIo", novena época, Primera Sala, Semanario Judicial de la Federación, octubre de 2004. 
sociales, conservando que no solo las autoridades deben acatar este mandato, sino que todas las personas están obligadas a respetarlo.

En 2006, en la Ley General para la lgualdad entre Mujeres y Hombres se instituye que "con el fin de promover la igualdad en el acceso a los derechos sociales y el pleno disfrute de éstos, serán objetivos de la política nacional el garantizar el seguimiento y la evaluación de la aplicación en los tres órdenes de gobierno, de la legislación existente, en armonización con instrumentos internacionales", ${ }^{20}$ siendo la política nacional de igualdad el mecanismo de coordinación entre los poderes del Estado y los tres órdenes de gobierno, para alcanzar dicha igualdad.

Asimismo, se establece una modificación importante y que establece un compromiso para las autoridades jurisdiccionales y para la ciudadanía de hacer efectivo el principio de igualdad, no sólo en los casos en los que se ha violado el derecho humano específico, sino en todos los procedimientos que lleven a cabo.

En 2007, la Ley General de Acceso de las Mujeres a una Vida Libre de Violencia ${ }^{21}$ establece las acciones en materia de prevención, atención, sanción y erradicación de la violencia contra las mujeres y tiene por objeto

establecer la coordinación entre la Federación, las entidades federativas, el Distrito Federal y los municipios para prevenir, sancionar y erradicar la violencia contra las mujeres, así como los principios y modalidades para garantizar su acceso a una vida libre de violencia que favorezca su desarrollo y bienestar conforme a los principios de igualdad y de no discriminación, así como para garantizar la democracia, el desarrollo integral y sustentable que fortalezca la soberanía y el régimen democrático establecidos en la Constitución Política de los Estados Unidos Mexicanos. ${ }^{22}$

Por su parte, el Reglamento de la Ley General de Acceso de las Mujeres a una Vida Libre de Violencia ${ }^{23}$ tiene como objeto "reglamentar las disposiciones de la Ley General de Acceso de las Mujeres a una Vida Libre de Violencia, en lo relativo al Poder Ejecutivo Federal, y las bases de coordinación entre éste, las entidades federativas y los municipios, necesarias para su ejecución". ${ }^{24}$

En el ámbito del principio de no discriminación, la Ley Federal para Prevenir y Eliminar la Discriminación establece la responsabilidad del Estado en la promo-

\footnotetext{
20 Artículo 38 de la Ley General para la Igualdad entre Mujeres y Hombres, última reforma publicada en el Diario Oficial de la Federación el 16 de junio de 2011.

${ }^{21}$ Ley General de Acceso a las Mujeres a una Vida Libre de Violencia, última reforma publicada el 28 de enero de 2011.

${ }^{22}$ Artículo $1^{\circ}$ de la Ley General de Acceso a las Mujeres a una Vida Libre de Violencia.

${ }^{23}$ Reglamento de la Ley General de Acceso de las Mujeres a una Vida Libre de Violencia. Reglamento publicado el 11 de marzo de 2008.

${ }^{24}$ Artículo $1^{\circ}$ del Reglamento de la Ley General de Acceso de las Mujeres a una Vida Libre de Violencia.
} 
ELIZARDO RANNAURO MELGAREJO

ción de las condiciones para que la libertad y la igualdad de las personas sean reales y efectivas, proveyendo que deben eliminarse los obstáculos que impiden o mermen el ejercicio de éstos. ${ }^{25}$

A la respecto y para evitar que existan ambigüedades o contradicciones, la misma ley nos afirma que no deben considerarse como discriminación, las acciones legislativas, educativas o de políticas públicas positivas o compensatorias que sin afectar derechos de terceros establezcan tratos diferenciados con el objeto de promover la igualdad real de oportunidades. ${ }^{26}$

El Acuerdo Nacional para la lgualdad entre Mujeres y Hombres, plasma el compromiso de los poderes federales Ejecutivo, Legislativo y Judicial, así como de las personas titulares de los gobiernos de las entidades federativas, para dar prioridad efectiva a la promoción de la igualdad de trato y oportunidades entre mujeres y hombres, así como la eliminación de todo tipo y modalidad de violencia contra las mujeres.

Asimismo, en las entidades federativas existe un avance significativo al publicar, en la mayoría de ellas, un cuerpo normativo con relación al derecho a una vida libre de violencia, la igualdad entre mujeres y hombres y no discriminación que vinculan una coordinación interinstitucional entre las dependencias de los gobiernos de las entidades federativas y gobiernos municipales.

\section{La armonización legislativa con perspectiva de género al derecho interno en México}

Al ser parte el Estado mexicano de la Convención de Viena sobre el Derecho de los Tratados, queda claro el compromiso de traducir los tratados internacionales con los ordenamientos jurídicos mexicanos, compromiso que se conoce como un proceso de "armonización legislativa"; sin embargo, en el país, existen diferentes conceptos de la armonización legislativa, uno de ellos es cuando se habla de

[...] coordinación de las distintas normas jurídicas eventualmente aplicables a la regulación de una relación de un tipo de relaciones jurídicas para lograr soluciones más adecuadas en el contexto internacional. Una relación jurídica que debe producir sus efectos en varios Estados puede ser regulada de manera diferente por los sistemas jurídicos con los cuales está vinculada, y estas diferencias pueden provocar soluciones

${ }^{25}$ Artículo $2^{\circ}$ de la Ley Federal para Prevenir y Eliminar la Discriminación, última reforma publicada en el Diario Oficial de la Federación el 27 de noviembre de 2011.

${ }^{26}$ Artículo $5^{\circ}$ de la Ley Federal para Prevenir y Eliminar la Discriminación, última reforma publicada en el Diario Oficial de la Federación el 27 de noviembre de 2011. 
totalmente dispares, respecto de su validez o de sus efectos; soluciones alejadas entre sí provocan que difícilmente se alcancen los resultados deseados.

Por esta razón se ha utilizado el concepto de armonización, para permitir que se tomen en consideración los distintos sistemas jurídicos con vista a lograr mayor seguridad jurídica y justicia en sus resoluciones.

La armonización del derecho no significa su unificación, sino la estructuración de un proceso más amplio, que haga compatibles normatividades distintas y que pueda ser aceptada por la mayoría. ${ }^{27}$

Otro concepto es el que se encuentra definido en el glosario del Instituto Nacional de las Mujeres como el

[...] procedimiento que tiende a unificar el marco jurídico vigente de un país, conforme al espíritu y contenido de los instrumentos internacionales de los derechos humanos. Para México, el Derecho Internacional de los Derechos Humanos es parte del marco jurídico nacional y se encuentra jerárquicamente por debajo de la Constitución y por encima de las Leyes Federales, por lo que es obligación que la norma interna sea coherente con lo expresado en los instrumentos internacionales de Derechos Humanos que México ha suscrito. ${ }^{28}$

Sin embargo y tomando sólo esos dos conceptos, es importante destacar que no solo hay que traducir los tratados internacionales en materia de derechos humanos a los ordenamientos jurídicos del país, o bien realizar la "armonización legislativa”, es necesario destacar que se debe de tomar en cuenta la condición y posición de las mujeres en su vida diaria y que ésta se regule en la norma jurídica mexicana, tal como y como se establece el concepto de armonizar en la agenda internacional, específicamente en los derechos humanos de las mujeres destacando lo siguiente:

En la Primera Conferencia Mundial del Año Internacional de la Mujer, ${ }^{29}$ los países decidieron promulgar principios a nivel nacional, regional e internacional para la consecución de la igualdad, el desarrollo y la paz, destacando la utilización del término de armonizar, en su Plan de Acción Mundial para la Consecución de los Objetivos del Año Internacional de la Mujer, en el marco de las esferas concretas para la acción nacional, ${ }^{30}$ y en particular en la esfera de la educación y formación, refiriéndose a la armonización a lo siguiente:

\footnotetext{
27 Diccionario jurídico mexicano, t. A-B, Porrúa-unam, México, 2007, pp. 342 y 343.

${ }^{28}$ Instituto Nacional de las Mujeres. Glosario de género, México, 2007, p. 21.

${ }^{29}$ Celebrada en México en el año de 1975.

${ }^{30}$ Las Esferas Concretas para la Acción Nacional son: Cooperación Internacional y Fortalecimiento de la Paz Mundial,
} 
[...] los programas ampliamente diversificados de educación profesional ya existentes y recién establecidos de todo tipo deberían ser accesibles en igual medida a ambos sexos, para ofrecer a muchachas y muchachos una amplia selección de oportunidades de empleos, incluso lo que requieres mayores aptitudes, y para armonizar las necesidades nacionales con las oportunidades de trabajo. ${ }^{31}$

Posteriormente, en el segundo informe de la Conferencia Mundial del Decenio de las Naciones Unidas para la Mujer: Igualdad, Desarrollo y $\mathrm{Paz}^{32}$ en el Programa de Acción a Nivel Nacional, particularmente en las Metas y Estrategias Nacionales para lograr una plena participación de la Mujer en el Desarrollo Económico y Social intitulado "Empleo, Salud y Educación", se refiere a la palabra de armonizar: "A fin de asegurar a hombres y mujeres la posibilidad de armonizar sus actividades profesionales con su vida familiar, se deberían crear servicios de cuidado de los niños y servicios de esparcimiento para adolescentes, reducir las jornadas de trabajo e introducir horarios flexibles". ${ }^{33}$

Así pues, en la Conferencia Mundial para el Examen y Evaluación de los Logros del Decenio de las Naciones Unidas para la Mujer: Igualdad, Desarrollo y $\mathrm{Paz}^{34}$ se señala en el apartado de igualdad en la participación política y la adopción de decisiones en el tema de armonización que

en cuanto al aumento del número de parejas empleadas conjuntamente en la administración pública, especialmente en el servicio exterior, se exhorta a los gobiernos a que tengan sus necesidades especiales, en particular el deseo de ambos integrantes de que se les asigne un mismo lugar de destino, a fin de armonizar sus obligaciones familiares y profesionales..$^{35}$

Una de las medidas globales sobre la armonización en el ámbito de la salud es "[...] orientar también los esfuerzos a la salud de las embarazadas y de las lactantes, a las repercusiones que las nuevas tecnologías tienen en la salud y a la armonización del trabajo con las responsabilidades familiares". ${ }^{36}$

En lo que respecta a los compromisos económicos, políticos, sociales, cultura-

218 les y jurídicos para que se logre el desarrollo social adquirido en las conferencias

Participación Política, Educación y Formación, Empleo y Funciones Conexas en la Economía, Salud y Nutrición, La Familia en la Sociedad Moderna, Población, Servicios de Vivienda y Afines, así como Otras Cuestiones Sociales.

31 Flores Romualdo, Deisy Magaly y Rannauro Melgarejo, Elzzardo. Compilación seleccionada del marco jurídico nacional e internacional de las mujeres, 3a. ed., SER-UNIFEM-PNUD, t. III, p. 38.

${ }_{32}$ Celebrada en Copenhague, Dinamarca, en 1980.

33 Flores Romualdo, Deisy Magaly y Rannauro Melgarejo, Ellzardo. op. cit., p. 109.

34 Segunda Conferencia Internacional de la Mujer, celebrada en Nairobi en 1985.

35 Flores Romualdo, Deisy Magaly y Rannauro Melgarejo, Elizardo. op. cit., p. 139.

${ }^{36}$ Ibidem, p. 199. 
internacionales, ${ }^{37}$ el Estado mexicano en el ámbito de la armonización se ha comprometido a:

[...] promover la estabilidad y las inversiones a largo plazo, velar por la competencia leal y la conduzca ética, y armonizar el desarrollo económico y social incluidas la formulación y la aplicación de programas apropiadas que habiliten y faculten a las personas que viven en la pobreza y a los desfavorecidos, especialmente, mujeres, para participar en forma plena y productiva en la economía y la sociedad. ${ }^{38}$

"Armonizar" o la armonización como un tema general, sin que se defina en el marco de reformas a la norma jurídica queda establecida en la Cuarta Conferencia Mundial de la Mujer, ${ }^{39}$ refiriéndose al objetivo estratégico F. "La Mujer y la Economía", el cual refiere "fomentar la armonización de las responsabilidades de las y los hombres en lo que respecta al trabajo y la familia”.

$\mathrm{Al}$ respecto, hay que destacar que la Unión Interparlamentaria Internacional $(\mathrm{UIP})^{40}$ refiere que las legislaciones nacionales deberán traducir los principios y objetivos de las Convenciones en cláusulas legales concretas y sitúan los objetivos y prioridades para la acción nacional a fin de establecer la igualdad entre hombres y mujeres.

A efecto de no confundir los diferentes términos antes señalados, es importante destacar que la armonización al derecho interno no es hablar de una simple homologación o armonización legislativa con la normatividad nacional, ni una recepción directa de los instrumentos internacionales en la legislación federal y local; sino que constituye todo un ajuste de estos compromisos y la situación de las mujeres y hombres en todos los entornos en que se desarrollan, con la finalidad de que todas las modificaciones propuestas se incluyan en el marco jurídico interno, y que al momento de que en la práctica se tengan que aplicar la normatividad propuesta, no surjan inconvenientes de tipo contradictorio con todo el marco jurídico interno: leyes generales, secundarias y orgánicas; códigos sustantivos y adjetivos; reglamentos internos y operativos; legislación federal, estatal y municipal.

\footnotetext{
${ }_{37}$ Conferencia Mundial sobre Desarrollo Social, Copenhague, Dinamarca, 1995.

38 Flores Romualdo, Deisy Magaly y Rannauro Melgarejo, Elizardo. op. cit., p. 368.

${ }^{39}$ Celebrada en Beijing, China, en 1995.

${ }^{40}$ Creada en el año de 1989, es la organización internacional de los parlamentos. Como tal, es la única organización que representa a la rama legislativa de los gobiernos en una escala mundial. Su propósito fundamental es promover la paz y la democracia a través del diálogo político. La uIP es el principal interlocutor parlamentario de las Naciones Unidas y lleva la voz de los parlamentos a los procesos de toma de decisión de las Naciones Unidas, presentando regularmente sus resoluciones a la Asamblea General. En el año 2002 las Naciones Unidas le otorgaron el estatus de observador permanente.
} 
De tal suerte que el impacto al que se requiere o queremos llegar es de realizar una propuesta de reforma con perspectiva de género y que involucre la situación de las mujeres y hombres, para el desarrollo y la paz en el Estado mexicano, libre de discriminación y desigualdad entre mujeres y hombres, evitando que en la norma interna exista la repetición o superposición de textos, detectar aquellas disposiciones discriminatorias que han dado lugar a la discriminación contra las mujeres, la no prevención, atención, sanción y erradicación de la violencia, independientemente de los problemas de interpretación existentes.

Con la finalidad de delimitar un concepto claro y oportuno para realizar la armonización política, social, cultural, ecológica y económica en la vida de las mujeres y los hombres con la normatividad, es oportuno señalar que se entenderá por armonización legislativa en el derecho interno: el establecer las necesidades y requerimientos de las mujeres y los hombres en la sociedad de conformidad con los compromisos adquiridos en los instrumentos internacionales de derechos humanos ratificados por el gobierno de México, a la norma interna a través de la concordancia de la norma jurídica mexicana en sus tres poderes y en sus órdenes de gobierno, el objetivo final es el armonizar las actividades diarias de la sociedad con la norma jurídica vigente.

Este proceso no es únicamente función del Poder Legislativo, también compete a los poderes Ejecutivo y Judicial, tanto en los ordenamientos jurídicos administrativos, ${ }^{41}$ como en las propuestas que remiten al ejecutivo, en tal sentido, debe implementares en los tres poderes del Estado y en los órganos que integran los tres órdenes de gobierno (federal, estatal y municipal) desde dos enfoques: al interior de las mismas instituciones y autoridades gubernamentales, a través de la igualdad laboral preponderantemente, así como en las funciones y atribuciones de cada institución, esto es, en las acciones positivas y políticas públicas que deben ejecutar en la materia.

El Poder Ejecutivo debe incorporar los multicitados principios al interior de las dependencias, mediante la implementación de una armonización legislativa con perspectiva de género a sus ordenamientos jurídico-administrativos, que promoverán una mejora en las relaciones humanas entre las personas que laboran en sus dependencias, así como para una planeación e implementación de acciones y políticas para alcanzar la igualdad entre mujeres y hombres y eliminar la discriminación.

${ }^{41}$ Los ordenamientos jurídico-administrativos pueden dividirse en dos vertientes: al interior y al exterior. Al interior son: acuerdos, convenios, circulares, oficios-circulares, manuales, instructivos, reglas, estatutos, contratos administrativos, condiciones generales, aclaraciones, resoluciones, órdenes, bases, politicas y lineamientos. Al exterior: decretos, programas, planes, norma oficial mexicana, normas mexicanas, normas técnicas, normas, declaratorias. 
Así como el Poder Ejecutivo debe promover cambios internos, el Poder Legislativo también se encuentra facultado para ello, a través del análisis y, en su caso, reforma a sus ordenamientos internos.

Aunado a lo anterior, el Poder Legislativo necesita analizar que todas leyes emanadas de él se encuentren vinculadas con la igualdad entre mujeres y hombres y con la no discriminación y, en caso contrario, promover su armonización legislativa con perspectiva de género, para evitar contradicciones, un sistema jurídico deficiente o ambiguo, que pueda traer como consecuencia un desconcierto legal o simplemente, el incumplimiento con los compromisos internacionales o atribuciones constitucionales. Además en todas aquellas iniciativas de ley se incorpore la perspectiva de género.

Por su parte, el Poder Judicial juega un rol importante en la protección y garantía de los derechos humanos, la igualdad entre mujeres y hombres y la no discriminación, apoyados también en el análisis o reformas de sus ordenamientos administrativos internos, pero particularmente en las funciones y atribuciones que desempeña, debido a que será él quien dirima las controversias que se susciten y, por ende, mediante la interpretación y ejecución de las leyes, resuelva conflictos entre los particulares y el Estado, así como entre los órganos y poderes del Estado con estricto apego a la legalidad y a la igualdad

Esto es, conlleva la responsabilidad de incluir en los procedimientos jurisdiccionales y en las resoluciones y sentencia los principios de igualdad y no discriminación, en los que deben considerarse las realidades actuales para emitir opiniones que no se encuentren contrarias a dichos principios.

La armonización legislativa con perspectiva de género, además, debe vincularse en el ámbito federal y estatal, debido a que las funciones y atribuciones de los Poderes de las entidades federativas provienen de una misma naturaleza jurídica.

En el ámbito municipal para el buen funcionamiento de los ayuntamientos como órganos deliberantes, la misma Constitución Política federal, así como las leyes orgánicas municipales, deben incorporar la atribución de resolver colegiadamente los asuntos de su competencia, mediante una sesión de cabildo (integrada por las personas con posibilidad de toma de decisiones al interior del Ayuntamiento), que pueden incorporar estos principios, a través de la emisión de reglamentos, acuerdos o manuales internos, como el análisis y reformas de bandos municipales y reglamentos municipales, por citar algunos ejemplos, que regulan las conductas entre las personas que habitan el municipio.

Debido a lo anterior, es necesario contar con una serie de metodologías de trabajo para la armonización legislativa con perspectiva de género al derecho interno, cada una de estas metodologías pueden ser utilizadas por el Poder 
Ejecutivo, Legislativo y Judicial, de los diferentes órdenes de gobierno, esto es federal, estatal y municipal, en los cuales se deberá incluir los datos generales del ordenamiento jurídico que se analiza, la selección del tratado internacional en materia de derechos humanos, especificando la redacción del o los artículos del tratado internacional que debe aplicarse al caso concreto, las observaciones y/o recomendaciones internacionales emitidas por los mecanismos de seguimiento de los tratados internacionales en materia de derechos humanos, la fundamentación de los ordenamientos jurídicos nacionales aplicables, y en su caso, la redacción de los ordenamientos jurídicos de las entidades federativas que pueden ser aplicables.

Por último, se transcriben todos aquellos y cada uno de los artículos seleccionados de la normatividad que se encuentra analizando para realiza la propuesta de reforma con perspectiva de género al derecho interno que se analiza.

Esta metodología se realizó de forma exitosa en un número amplio de acciones realizadas con base en proyectos de carácter internacional y del gobierno de México, bajo la coordinación de las entidades federativas, los cuales han dado como resultado diversas propuestas con perspectiva de género al derecho interno mexicano, entre las que destacan la creación de la Ley para Prevenir, Atender, Combatir, Sancionar y Erradicar la Trata de Personas del Estado de Veracruz y la reforma a diversas disposiciones del Código Penal y del Código de Procedimientos Penales del Estado de Veracruz, el Código Civil y Código de Procedimientos Civiles del Estado de Veracruz, ${ }^{42}$ actualmente publicadas y vigentes, así como diversos ordenamientos jurídicos del estado de Veracruz que regulan las funciones y atribuciones de los ayuntamientos, desde la normatividad orgánica hasta aquellas que regulan funciones especificas para impulsar la igualdad entre mujeres y hombres y la no discriminación. ${ }^{43}$

En el año 2010, en el estado de Chihuahua se realizó con esta metodología del Poder Ejecutivo Federal, la Propuesta de Reglamento de la Ley de Igualdad entre Mujeres y Hombres del Estado de Chihuahua, ${ }^{44}$ que actualmente se encuentra en discusión para su posible aprobación, además de sensibilización y २२२ capacitación a las autoridades al servicio público en las entidades federativas de Coahuila, Estado de México y Tlaxcala, entre otras, que dio como resultado la publicación de algunos medios que guían estas acciones.

\footnotetext{
42 López Velázouez, Aldo Francisco y Rannauro Melgarejo, Elizardo. Armonización legislativa al derecho interno del estado de Veracruz, Instituto Veracruzano de las Mujeres, México, 2009.

43 López Velázquez, Aldo Francisco y Rannauro Melgarejo, Elzardo. Armonización legislativa con perspectiva de género al derecho interno del estado de Veracruz para el desarrollo municipal, Instituto Veracruzano de las Mujeres, México, 2010.

${ }^{44}$ Rannauro Melgarejo, Elizardo. Propuesta de Reglamento de la Ley de lgualdad entre Mujeres y Hombres del Estado de Chihuahua, Instituto Chihuahuense de las Mujeres, México, 2010.
} 
Durante 2004 y 2005 se realizaron las propuestas de reforma a los códigos penales y de procedimientos penales y las leyes de asistencia social de todas las entidades federativas del país, como un primer acercamiento al procedimiento de armonización legislativa con perspectiva de género al derecho interno mexicano.

\section{Conclusiones}

Se han construido avances en la agenda internacional. Los países han adoptado tanto en el Sistema Universal como en el Sistema Interamericano acuerdos para garantizar que en todas sus actuaciones incluyan el derecho a la igualdad entre mujeres y hombres y el principio a la no discriminación, a efecto de proteger los derechos humanos, particularmente para la autonomía de las mujeres.

En México, se encuentran establecidos los principios de igualdad entre mujeres y hombres y no discriminación desde el ámbito constitucional, así como en diversos ordenamientos jurídicos a nivel federal y estatal como ejes rectores que señalan las funciones y atribuciones de las autoridades, así como las obligaciones para realizar la armonización legislativa al derecho interno en México; sin embargo, para modificar los patrones culturales en las autoridades mexicanas y en el ser y quehacer de las dependencias, así como en los ordenamientos jurídicos que regulan el comportamiento de la sociedad mexicana, es necesario primero conocer los ordenamientos jurídicos aplicables a nivel nacional y los acuerdos internacionales de los que México es parte.

Además, es necesario y fundamental incorporar la perspectiva de género en la armonización legislativa al derecho interno en México, así como en las propuestas de reforma, identificando los compromisos internacionales y los ordenamientos jurídicos aplicables para eliminar la desigualdad y la no discriminación, esto es, respetando los derechos humanos de las mujeres y hombres.

En diferentes ocasiones, se puede sostener que las condiciones que han obstaculizado el avance de la elaboración de propuestas con perspectiva de género para la reforma legislativa al derecho interno, o bien, en la creación de normas con perspectiva de género, son: el origen de la propuesta, la necesidad de consenso para la toma de decisiones, las diferencias en el sistema de incorporación del derecho en su ámbito local, la jerarquía de la normatividad nacional e internacional con relación a la legislación interna, ausencia de plazos para su incorporación, entre otras, que desmotivan que se impulse este proceso.

Hay que reconocer que uno de los principales obstáculos es vincular las obligaciones contenidas en el ámbito internacional y nacional, a la autoridades de los poderes y órdenes del Estado, debido a la falta de voluntad, desconocimiento 
ELIZARDO RANNAURO MELGAREJO

o reducida capacitación, que pueda hacer cumplir el compromiso de adoptar medidas, incluso de carácter legislativo para la inclusión de estos derechos.

Aunando a lo anterior, unos de los principales retos es traducir y aplicar de facto las obligaciones contenidas en las reformas constitucionales de 2011, como un mecanismo de partida que consagrara una protección de los derechos humanos y, por ende, la igualdad entre mujeres y hombres y no discriminación real y efectiva.

Por consiguiente, las leyes mexicanas sobre la prevención de la discriminación, las leyes de acceso de las mujeres a una vida libre de violencia y las leyes para la igualdad entre mujeres y hombres, son el detonante de las políticas naciones y estatales en esta índole.

Por lo tanto, es necesario hacer visible que estos derechos deben encontrase explícitamente citados en la normatividad interna de los países, incluidos México, a través de la ejecución del proceso de armonización legislativa con perspectiva de género al derecho interno, que incluyan todo un mecanismo de protección de los derechos humanos y la inclusión de la igualdad y no discriminación, como formas de eliminar las problemáticas sociales y consolidar el desarrollo económico, político, social, cultural y medio ambiental.

Asimismo, no solo es reformar o crear leyes a conveniencia, sino también lograr una armonización en la vida de las personas que habitan un territorio, que haga posible un desarrollo humano y comunitario que respete la dignidad humana.

Sin duda, es necesario que los poderes del Estado y los tres órdenes de gobierno reconozcan los compromisos adquiridos en la agenda internacional en materia de igualdad y no discriminación, además de aquellos que protegen los derechos humanos, con la finalidad que se impulse el proceso de armonización legislativa al derecho interno mexicano que coadyuve al desarrollo humano, social, económico y cultura, y que fortalezca el Estado de derecho y la democracia en México. 